Nikola Korunović, Cristiano Fragassa, Dragan Marinković, Nikola Vitković, Miroslav Trajanović

\title{
Performance evaluation of cord material models applied to structural analysis of tires
}

Journal article | Accepted manuscript (Postprint)

This version is available at https://doi.org/10.14279/depositonce-10674

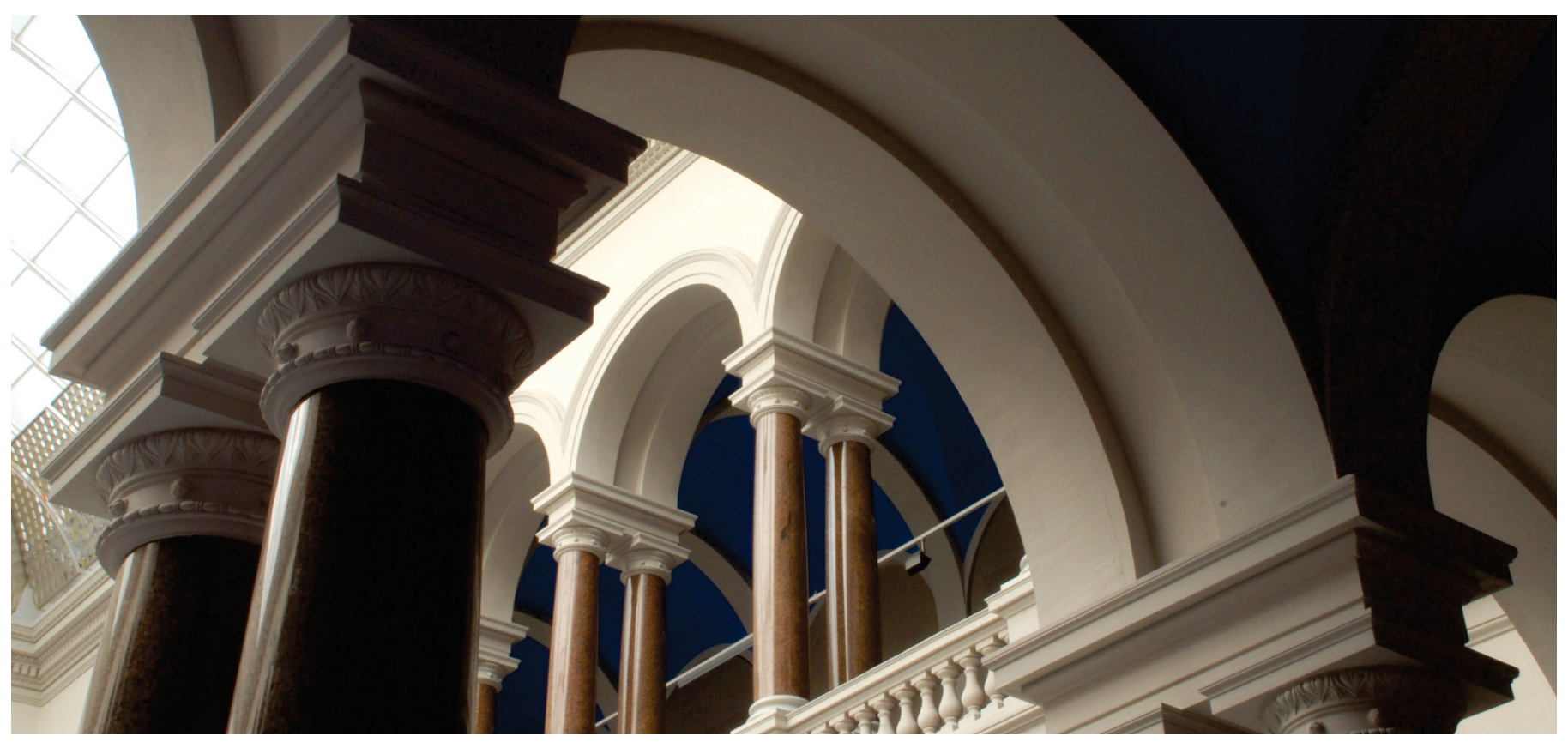

Korunović, N., Fragassa, C., Marinković, D., Vitković, N., \& Trajanović, M. (2019). Performance evaluation of cord material models applied to structural analysis of tires. Composite Structures, 224, 111006. https://doi.org/10.1016/j.compstruct.2019.111006 


\title{
Performance Evaluation of Cord Material Models Applied to Structural Analysis of Tires
}

\author{
Nikola Korunović $^{1, *}$, Cristiano Fragassa ${ }^{2}$, Dragan Marinković ${ }^{3}$, Nikola Vitković ${ }^{1}$ and Miroslav \\ Trajanović ${ }^{1}$ \\ 1 University of Niš, Faculty of Mechanical Engineering; \\ nikola.korunovic@masfak.ni.ac.rs; vitko@masfak.ni.ac.rs ; miroslav.trajanovic@masfak.ni.ac.rs \\ 2 University of Bologna, Department of Industrial Engineering; cristiano.fragassa@unibo.it \\ 3 TU Berlin; Department of Structural Analysis; dragan.marinkovic@tu-berlin.de
}

\begin{abstract}
Tires are, in essence, a composite structure made of reinforced elastomers. As in other composite structures, the accuracy of finite elements (FEs) in predicting the performance of a tire is highly dependent on the validity of the material models chosen to describe the mechanical behavior of its constituents. This paper concentrates on the material modeling of tire reinforcements, and analyzes several material models, namely linear, Yeoh and Marlow, which are quite common in these investigations. A realistic tire is considered as a general system and the most relevant results are discussed concerning precision, computational efficiency and complexity in parameters identification. The advantages of non-linear material models, especially of the Marlow model, are outlined. To the authors' knowledge, no study has addressed the abovementioned aspects of the application of tire cord models in FE analysis of tires in such detail or directly compared the performance of cord models in a realistic example.
\end{abstract}

Keywords: tire design; tire cord; material models; reinforced elastomers; finite element modeling

\section{Introduction}

The pneumatic tire is usually composed of a dozen of structural components, joined together and even slightly overlapped during the vulcanization process, which are either made of rubber or rubber-based composites [1, 2]. It represents a preloaded composite structure that gains its stiffness from textile and steel cord, embedded in rubber matrix and loaded by pressurized air. Depending on the tire construction, its reinforcing structural components are typically body cords (carcass), belt cords, bead wire and cap (overlay) ply [3] (Figure $1)$.

Structural reinforcements of tires may be regarded as fiber-reinforced polymer composites [4]. Because of the relatively large dimensions of fibers (tire cords) compared to the dimensions of the rubber matrix, they may be put into a subgroup of wire-reinforced composites. Due to a large volume fraction of steel wire compared to the rubber matrix, bead wire has specific properties and it is often treated as a solid steel component. Belt cords, in general, represent a twisted structure alternatively comprised of filaments (two or more), a combination of strands (filaments twisted together), or of strands and filaments [5]. Body ply cords are usually single filaments made of rayon or polyester, while cap plies represent single filaments, typically made of nylon. Aramid may also be used for belt or stabilizer ply material as a lightweight alternative to steel cord.

Tire designers widely rely on advanced design techniques, including finite element analysis (FEA) to predict and optimize car and tire behavior using virtual prototyping [6,7]. Structural static analysis, as in [8-10], implicit or explicit dynamic analysis, e.g. [8, 11, 12], or coupled thermo-mechanical analysis of tires, e.g. [13, 14], may be performed, and also serve as the means for virtual experimentation in the structural optimization process, e.g. $[15,16]$. In FEA of tires, structural reinforcements may be modeled using a number of different methodologies, where two approaches generally prevail: modeling based on composite materials theory [17] and separate modeling of the rubber matrix and cords using "rebar" elements [18] (Figure 1). The accuracy of tire FEA is highly dependent on the accuracy of material models used in finite element (FE) model building. Material modeling of rubber, with the goal of representing the complex viscoelastic/viscoplastic behavior, has been a topic of intensive research for many years, and various rubber models have been used in FEA of tires [19, 20]. At the same time, the mechanical behavior of tire cord has often been simplified and represented using 
linear, e.g. [21], bilinear [9, 22] or tension-only elastic material models. Although such estimations are often sufficient for a global prediction of tire behavior, it is rational to assume that significant errors in the estimation of local strain, stress, and strain energy may result from the use of simplified models. Various cord models also differ in terms of accuracy, speed, ease of use etc., which may be very important for the overall performance of numerical analysis of tires.

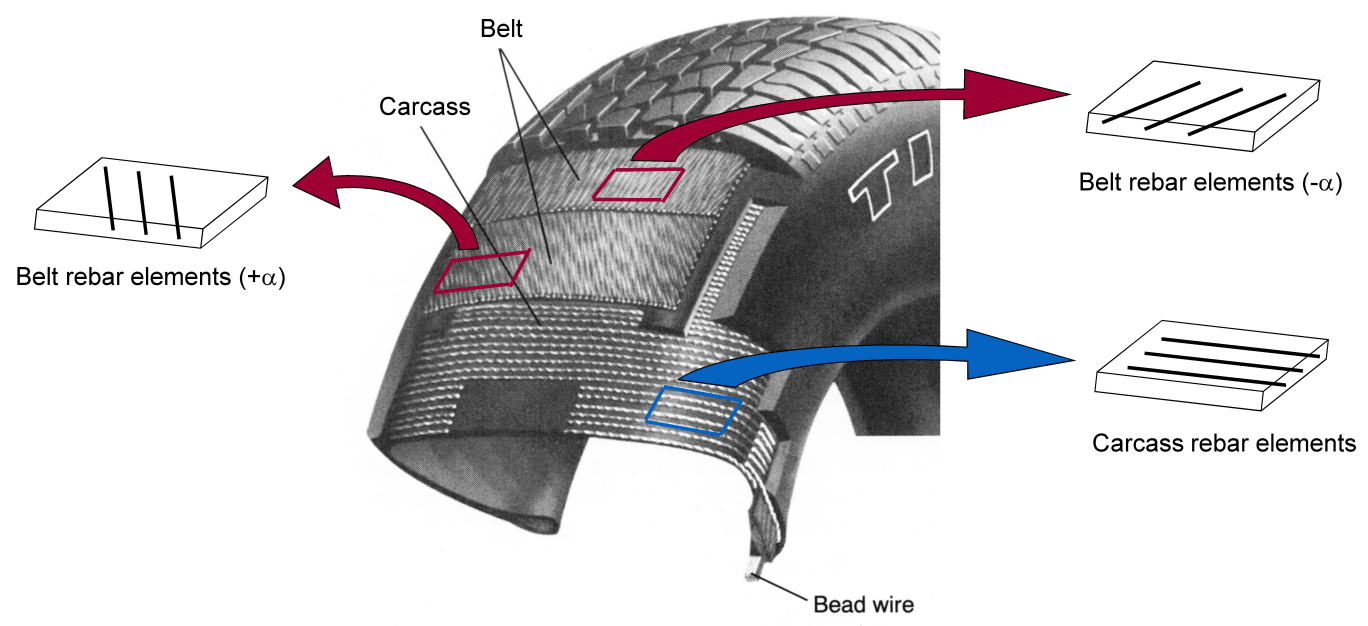

Figure 1. Reinforcing structural components of a radial pneumatic tire, with a schematic display of rebar elements used to model those in FEA. There usually exists one more reinforcement layer with a circumferentially oriented cord, placed between the belt and the tire tread, named cap (overlay) ply (tire image source: [23])

To gain a deeper insight into material modeling of tire cord and produce further reference related to the application of cord models in tire design, several commonly used material models are assessed and compared concerning modeling accuracy, computational efficiency and the effort needed for parameter identification. Test methods used for the collection of data necessary for material modeling are also briefly described. The results of structural analyses conducted using finite element models of a realistic tire containing various cord models are compared and discussed. Through the mentioned examples, the advantages of non-linear material models, especially of the Marlow model, are clearly outlined.

\section{Materials and Methods}

\subsection{Mechanical Properties of Tire Cord in Tension/Compression}

Considerable nonlinearity of stress-strain curves can be noticed in all textile cords, high elongation steel cords and other kinds of cords. Hysteresis loops of four different textile cords, loaded by the force of $20 \mathrm{~N}$ and then unloaded, are shown in Figure 2, according to [24].

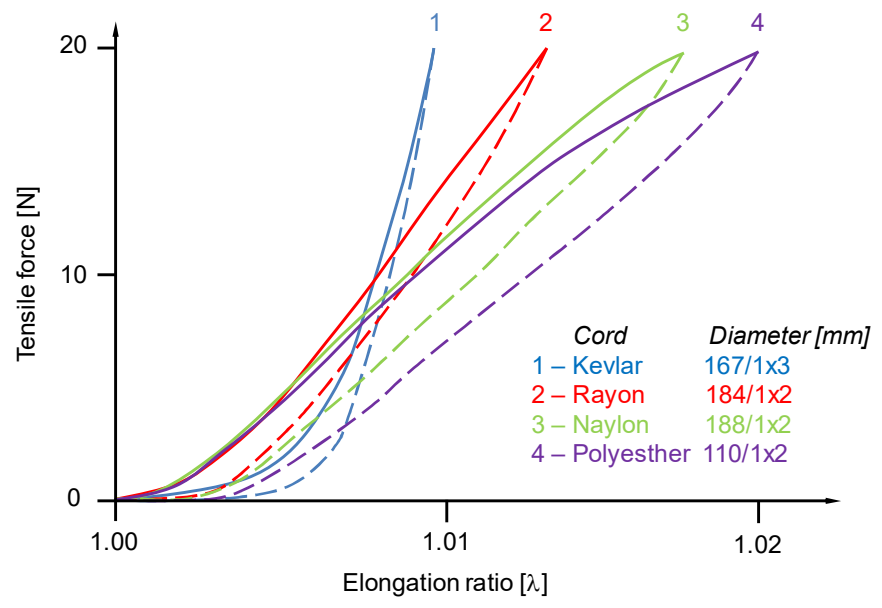

Figure 2. Loading and unloading curves of different textile cords, according to [24]. 
Tensile curves of various steel cords, also according to [24], are shown in Figure 3. The curves are nearly linear, up to $1 \%$ strain at least. The strength of cord fiber steel is significantly higher than that in common steels of similar composition due to the technology of drawing the rod. Though the hysteresis in steel cords is considerable, it is difficult to precisely record the unloading curve with a common tensile testing machine. It is reported by Koutny [24] that the attempts to find a suitable and simple method for measuring hysteresis of steel cord were unsuccessful.

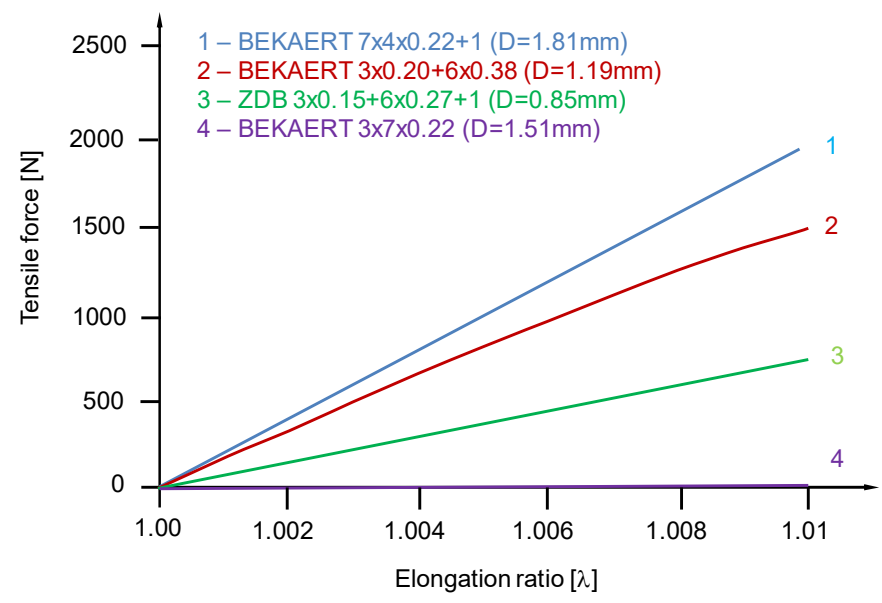

Figure 3. Tensile curves of several steel cords, according to [24].

A typical stress-strain curve of high-elongation (HE) steel tire cord in tension may be divided into three parts (Figure 4). At low strains the slope of the curve is relatively small, then it rises and for a wide range of strains stays nearly linear, while at larger strains the slope begins to fall. This is the consequence of the tire cord structure. As cord filaments are twisted, in lower tension they become partly loose [Figure $\mathbf{5}$ a]. The resulting modulus is thus very low while spatial packing of the primary fibers takes place. In higher tension, cord filaments get packed and tightened [Figure 5 b], the extension curve becomes nearly linear, and the modulus gets higher and stays constant for a while. When the stress gets closer to the ultimate strength of steel, the modulus gets smaller, and the material may yield, thus some permanent strain may remain present. At higher compressive stresses filament buckling occurs, and the resistance of cord abruptly becomes considerably smaller.

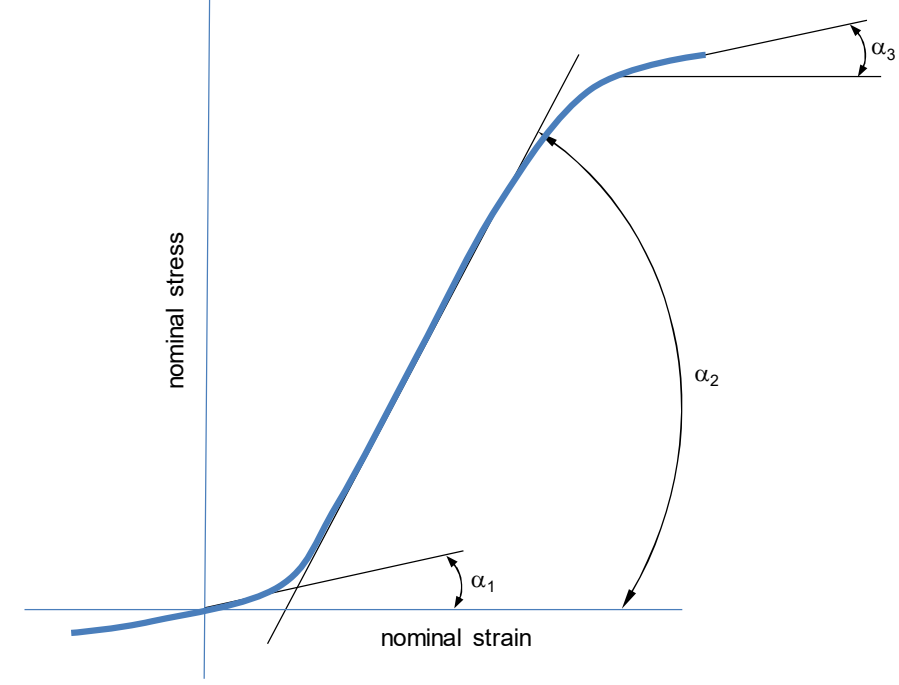

Figure 4. Difference in apparent elastic modulus of steel tire cord at low and high strains. 


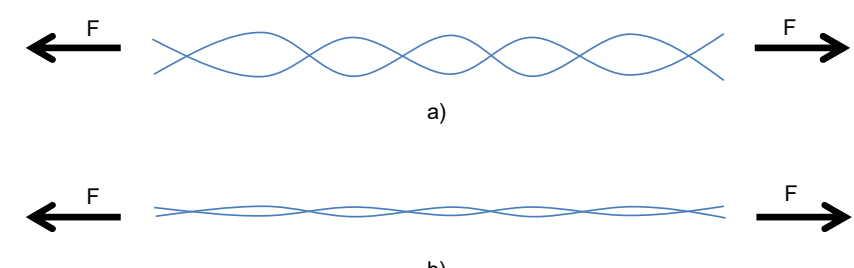

b)

Figure 5. Relative position of cord filaments at lower and higher cord tension.

The reinforcing function of polymer cords in a rubber matrix under compression was studied by Du et al. [25]. They found that polymer cords contribute to composite stiffness to a certain extent, i.e. that when the volume fraction of the cord in the cord-rubber composite is large enough, the properties of the cord-rubber composite are mostly influenced by those of the cord.

Viscoelastic behavior of tire cord is notable and, in some cases, may not be neglected. This is obvious from creep and stress relaxation tests described in [26]. Mechanical properties of tire cord are also strongly dependent on the temperature $[24,27]$. Thus, the material properties of cord, used in FEA, should be equivalent to the ones found inside the cured tire and not to the ones of the raw specimens, as those were not subjected to high temperature and undergone thermal shrinkage.

\subsection{Notes on Test Methods for Determination of Mechanical Properties of Tire Cord}

The estimation of typical cord stresses in loaded tires, based on FEA of different tire models, showed that cord stress values in most cases correspond to the nonlinear part of a typical cord stress-strain curve and that they are often negative. Thus, the general conclusion was reached that before material modeling for FEA of tires is performed the accurate uniaxial extension-compression curves for steel and textile cords must be obtained. It must be noted that the accurate stress-strain curves of tire cord in the whole range of possible strains are not easy to obtain and that they are not generally available in the literature or on request from cord manufacturers.

Standard test methods used to determine mechanical properties of tire cord are mostly designed with the purpose of acceptance testing of commercial shipments and they usually yield the values of the initial modulus or modulus in fixed force intervals, which are extracted from the nearly linear part of stress-strain curves. Thus, they are often not suitable for the determination of cord characteristics necessary for FEA of tires. Nevertheless, standard testing methods may be used as the base for the definition of the ones dedicated to FEA. For example, the procedures described in Steel cord test methods D 2969 [28] and Organic-base fibers test methods D 885 D885M [29] can still be beneficial considering cord sampling (sample choice, size, moisture prevention, preparation etc.), specimen conditioning (bringing textile cords to moisture equilibrium) or choice of apparatus (properties of a tensile testing machine and clamps).

When tire cord is tested for FEA, detailed stress-strain curves should be recorded, covering the whole range of strain that is expected in future analyses. A standard tensile testing machine and clamps should be sufficient for the task, as the part of the curve near breaking point is not taken into account. The use of an extensimeter in the middle part of the specimen should be a better option than direct measuring of clamp displacement. Stressstrain points should be recorded electronically and exported to a text file, for later use in material modeling procedures. As belt cords may be subjected to tension during the tire manufacturing process [30], it may be appropriate to impose a certain amount of preload in the beginning of the test, or to slightly adjust (shift) the stress and strain values of the test data obtained without preload. In order to enable the use of viscoelastic/viscoplastic cord models, the unloading curve should also be recorded. Depending on the cord type, tire type and parameters of the curing process, the effects of exposure to high temperature or moisture should be taken into account.

\subsection{Approaches to Modeling of Tire Reinforcements}

According to the theory of composite materials-based approach, fiber reinforced composites may be studied using micromechanical or macromechanical methods. Both methods may be useful in tire design, but there exist certain difficulties in their application. Micromechanical models require a considerable modeling effort and usage of very small finite elements. Thus, they are limited in size and mostly used for the prediction of 
equivalent properties of composite layers or submodeling. Macromechanical models require the determination of equivalent properties of composite material, using theoretical, micromechanical or experimental methods, which are then input as parameters of anisotropic or orthotropic material used to model the reinforcements. This process may produce very accurate results, but it may require a lot of effort and time in the model preparation phase. Still, the favorable feature of macromechanical models is that they may capture various couplings between deformation modes of fiber reinforced composites.

Shield and Costello studied the mechanical behavior of a cord-composite plate in uniaxial tension and pure bending, and developed equations for the calculation of equivalent technical constants [31,32]. This model took into account the construction of the cord, which consisted of several twisted filaments. Pidaparti embedded the mentioned equations into a special type of finite element, designed to analyze the behavior of the rubber cord, primarily its behavior in twisting [33]. By analyzing the FE model containing two layers of rubberized cord separated by a thin layer of rubber, he obtained the results that were close to those that Shield and Costello obtained analytically for the same construction. Kocak and Pidaparti used a micromechanical FE model to examine the influence of fiber shape on the mechanical properties of the rubber-based composite [34]. They concluded that the non-circular cross-section of the cord contributes to a significant rise in stress along the cordrubber interface and changes the locations of maximal stress. Yintao et al. developed an approach for automatic creation of detailed FE models of multi-strand cord structures, based on design parameters such as lay length and the radius of the strand center line [35]. They modeled the steel cords of a truck tire and subjected them to experimentally determined loading conditions. In addition to a good agreement between the experimental and numerical results, they were also able to find some interesting local deformation and stress patterns under combined tension and bending.

The macromechanical approach to the modeling of cord-rubber composites has been present in tire design for a long time. For example, Walter et al. [36] applied composite materials theory to investigation of multi-ply cord-reinforced rubber composites, specific to tires. Based on the developed equations, they were able to predict some trends in tire performance parameters related to the tire tread region. A number of tire stress and deformation theories, e.g. [37, 38], were also based on the theory of composite materials. Advances in finite element method (FEM) and development of computers introduced FEA to tire design and the aforementioned theoretical knowledge was combined with numerical methods, as reviewed by Ridha [39, 40]. More recent examples of the macromechanical approach to the modeling of tire reinforcements include the calculation of effective mechanical properties of rubber-cord composites performed by Levin [41].

"REBAR" (REinforcement BAR) elements (Figure 1) were primarily developed for FEA of reinforced concrete and then adapted for analysis of rubber composites [18]. The main concept behind REBAR elements is the separate modeling of the matrix and reinforcements in fibrous composites. The main advantage of this concept is that the material of both components may be modeled using separate material laws, i.e. constitutive relations, as well as different failure criteria (e.g. cracking for rubber and plastic flow for steel cord). One or more layers of reinforcing fibers inside a REBAR element are in fact approximated by a thin homogenous layer of material with equivalent material properties. Thus, the number of reinforcing layers need not influence the number of degrees of freedom in an FE model. As fiber thickness is usually small compared to the dimensions of the modeled structure, bending stiffness of reinforcements is usually neglected. Although this approach fails to capture some of the coupling effects inside the composite material, it was found to be very convenient in FEA of tires, as it simplifies and accelerates the preparation of FEM models. Compared to other types of finite elements, rebar elements are also modest in demands toward computing resources and reduce discretization errors [42].

Rebar elements were introduced to FEA of rubber composites and tires by Helnwein at al. [18]. Since then, they have been extensively used in tire analysis, e.g. [8, 9, 42, 43], and introduced to commercial finite element codes, such as Abaqus [44] or MSC Marc [45], as a standard option in tire modeling. Improvements in various aspects of rebar-based modeling have also been made. For example, various hyperelastic formulations of rebar material, namely two variants of the Neo-Hooekean model and the quadratic logarithmic model were explored by Meschke et al. [46]. Tönük et al. [22] designed a subroutine for determining the angles of the cord within the 3D rebar elements for tire analysis performed in Msc. MARC. Behnke and Kaliske proposed a temperature- and deformation dependent nonlinear elastic cord model formulation [47]. The parameters of the proposed model could be directly derived from cord tensile tests data obtained at different temperatures.

Cho et al. [30] studied truck tire stress using a global-local approach to FEA. In order to represent cord tension as well as cord bending, the results obtained using a global tire model were used to impose boundary 
conditions on the local tire model, which employed one of the equivalent cord models proposed in the study. By use of equivalent cord models, the shear strains at the belt edges could be accurately predicted, which was found to be beneficial in the assessment of tire durability. Multiscale modeling was also employed by Behroozinia et al. [48] to provide the theoretical predictions for damage development [49] in the cord-rubber composites in tires. A new three-dimensional model of the cord-rubber composite was developed and used for the prediction of different types of damage including matrix cracking, delamination, and fiber failure based on the micro-scale analysis.

\subsection{Material Models of Tire Cord Considered in the Study}

Three material models were selected for a mutual comparison in a realistic tire design example: linear (tension-only), Yeoh and Marlow. Those models are frequently used for the description of cord as they are suitable for the identification of model parameters (curve fitting) using only the uniaxial data.

\subsubsection{Linear Material Models}

The simple linear material model (Figure 6 a) is characterized by the identical elasticity modulus $\mathrm{E}$ in tension and compression. It is the simplest one to use and offers a good first approximation of cord elasticity, but it fails to capture the nonlinear behavior of cord around zero strain as well as micro-buckling of cord in compression. For example, an FE tire model based on a simple linear cord model was used by Ghoerishi for rolling tire FEA [50].

The bilinear material model (Figure 6 b) is able to approximately model micro-buckling, by introducing separate elastic moduli in tension and compression. For example, Tönük used a bilinear material model to represent textile cord used in a carcass [22].

The tension-only linear material model (Figure $6 \mathrm{c}$ ), which assumes that the elastic modulus in compression equals zero [44], may also be used to model textile cord found in a tire carcass.

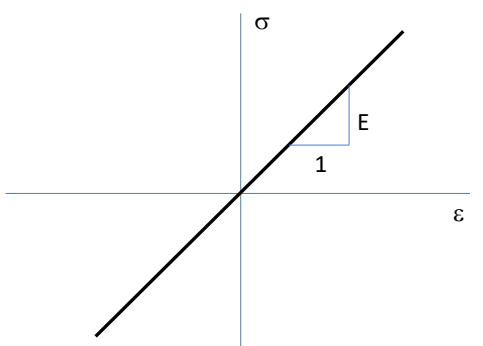

(a)

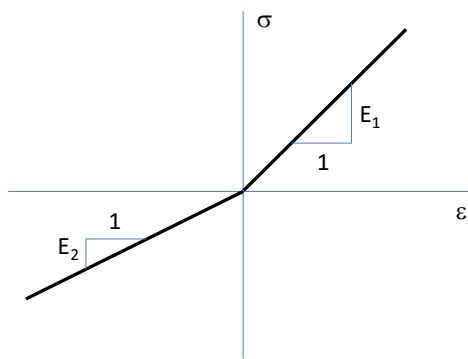

(b)

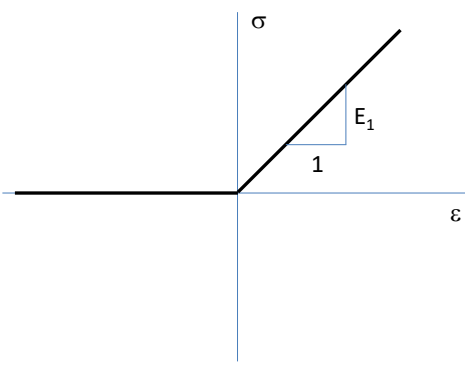

(c)

Figure 6. (a) Linear, (b) bilinear and (c) tension-only material models.

Linear material models may be used to approximately model elasticity of tire cord types that do not exhibit significant nonlinear behavior. Nevertheless, if they are used to model cord types characterized by pronounced nonlinear behavior, significant errors may appear in subsequent finite element analyses. Besides their inability to accurately approximate uniaxial tension-compression curves, linear material models are not able to capture the viscoelastic/viscoplastic behavior of cord that may be very significant, especially in dynamic analyses.

\subsubsection{Non-Linear Material Models}

Both non-linear models selected for comparison are hyperelastic, i.e. constitutive models for ideally elastic material for which the stress-strain relationship is derived from a strain energy density function $(W)$ [51]. Testing the application of various material models to rubber analysis, Gough et al. [52] showed that there is always a trade-off between the accuracy of the calculated material parameters, number of experiments and types of rubber specimens. They found that the computed parameters from simple uniaxial tests for models that depend on the first invariant of strain tensor i.e. $I_{I}$ (like Yeoh [53, 54] and Marlow [55]), are generally more accurate than for those which are based on $I_{I}$ and $I_{2}$ or principle stretch ratios (such as Ogden [56]). This was further corroborated by Ghoreishy [57]. He found that the Marlow model had the highest prediction accuracy if only uniaxial data exist. Furthermore, he found that the Arruda-Boyce, Gent and Yeoh models had lower prediction accuracy at large strains than the Marlow model, if only uniaxial data exist. 
The Yeoh material model is a typical representative of polynomial hyperelastic models that generally offers a good trade-off between accuracy and stability. In this study, it was used in the form that accounts for compressibility [44]:

$$
W=C_{10}\left(\bar{I}_{1}-3\right)+C_{20} \bar{I}_{1}-3^{2}+C_{30}\left(\bar{I}_{1}-3\right)^{3}+\frac{1}{D_{1}}\left(J_{e l}-1\right)^{2}+\frac{1}{D_{2}}\left(J_{e l}-1\right)^{4}+\frac{1}{D_{3}}\left(J_{e l}-1\right)^{6}
$$

where $\mathrm{W}$ represents the strain energy per unit of reference volume, $C_{i 0}$ and $D_{i}$ represent the temperaturedependent material parameters, $\bar{I}_{1}$ is the first deviatoric strain invariant, defined as

$$
\bar{I}=\bar{\lambda}_{1}^{2}+\bar{\lambda}_{2}^{2}+\bar{\lambda}_{3}^{2}
$$

where $\bar{\lambda}_{i}$ are the deviatoric stretches, $\bar{\lambda}_{i}=J^{-1 / 3} \lambda^{i}, J$ is the total volume ratio, $J^{\text {el }}$ is the elastic volume ratio, $J^{e l}=J /\left(1+\varepsilon^{t h}\right)^{3}\left(\varepsilon^{t h}\right.$ is the linear thermal expansion strain that is obtained from the temperature and the isotropic thermal expansion coefficient) and $\lambda^{i}$ are the principal stretches. In this study, the parameters $C_{i 0}$ were calculated using uniaxial test data and the compressibility related parameter $D_{l}$ was calculated by providing Poisson's ratio $v$.

$$
D_{1}=\frac{3(1-2 v)}{2 C_{10}(1+v)} .
$$

The Marlow material model represents a unique hyperelastic model, which strictly follows the experimental data [44]. Generally, in order to use hyperelastic material models in FEA software, one can either directly specify material model parameters or provide experimental test data and have the software automatically determine the appropriate values of the parameters. In the case of the Marlow model, the test data directly characterize the strain energy potential (there are no material coefficients for this model). It is also best suited for the modeling of mechanical components in which one specific state of strain prevails. This is exactly the case in tire cord, which is mostly subjected to uniaxial tension, thus only the uniaxial test data can be used as the input for material modeling. It was also used in the form that accounts for compressibility [44]:

$$
W=W_{\text {dev }}\left(\bar{I}_{1}\right)+W_{v o l}\left(J_{e l}\right)
$$

where $\mathrm{W}$ is the strain energy per unit of reference volume, $W_{d e v}$ represents its deviatoric part and $W^{\text {vol }}$ its volumetric part. $\bar{I}_{1}, \bar{\lambda}_{i}, J^{e l}$ and $\lambda^{i}$ are defined in the same way as with the Yeoh model. In this study, the deviatoric part of strain energy potential was defined by providing uniaxial test data while the volumetric part was defined by providing Poisson's ratio.

\subsection{Identification of Material Model Parameters of Various Tire Cord Models}

In order to obtain material model parameters, the test data published in [58] was used. Only uniaxial tension/compression data was used, as uniaxial stress prevails in tire cord (which is especially true for carcass cord). The compressibility of cord was modeled using Poisson's coefficient. The test data curve used for the carcass and cap ply cord modeling was the tension curve for Nylon 66, shown in Figure 7. The data points extracted from the curve are given in Table $\mathbf{1}$. 


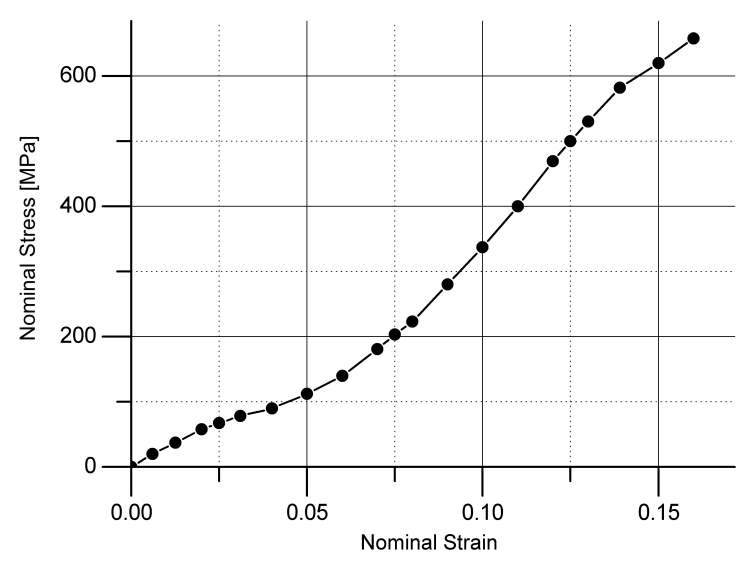

Figure 7. Test data approximated from Nylon 66 curve [58].

Table 1. Data points approximated from nylon cord tension curve shown in Figure 7. The third column represents the smoothed stress data obtained during the Marlow model fitting with the data smoothing option, level 3, turned on.

\begin{tabular}{ccc}
\hline $\begin{array}{c}\text { Nominal } \\
\text { strain }\end{array}$ & $\begin{array}{c}\text { Nominal } \\
\text { stress [MPa] }\end{array}$ & $\begin{array}{c}\text { Nominal stress } \\
\text { smoothed [MPa] }\end{array}$ \\
\hline 0.0000 & 0.0 & -6.3274 \\
0.0060 & 20.0 & 0 \\
0.0125 & 37.0 & 15.429 \\
0.0200 & 58.0 & 33.43 \\
0.0250 & 67.0 & 53.09 \\
0.0310 & 78.0 & 64.538 \\
0.0400 & 90.0 & 76.727 \\
0.0500 & 112.0 & 93.751 \\
0.0600 & 140.0 & 115.24 \\
0.0700 & 181.0 & 143.4 \\
0.0750 & 203.0 & 180.25 \\
\hline
\end{tabular}

\begin{tabular}{ccc}
\hline $\begin{array}{c}\text { Nominal } \\
\text { strain }\end{array}$ & $\begin{array}{c}\text { Nominal stress } \\
{[\mathrm{MPa}]}\end{array}$ & $\begin{array}{c}\text { Nominal stress } \\
\text { smoothed [MPa] }\end{array}$ \\
\hline 0.0800 & 223.0 & 201.95 \\
0.0900 & 280.0 & 225.8 \\
0.1000 & 337.0 & 279.27 \\
0.1100 & 400.0 & 339.23 \\
0.1200 & 469.0 & 403.28 \\
0.1250 & 500.0 & 467.8 \\
0.1300 & 530.0 & 498.83 \\
0.1390 & 582.0 & 528.52 \\
0.1500 & 620.0 & 576.94 \\
0.1600 & 658.0 & 625.36 \\
\hline
\end{tabular}

The linear fit on test data is shown in Figure 8. The fit was performed using a limited number of points, covering the range of strains expected in tire analysis $(0-0.05)$. The elastic modulus of $2394.86 \mathrm{~N} / \mathrm{mm}^{2}$ in tension was obtained. In compression the modulus was chosen to be zero, i.e. the tension-only material model was defined. 


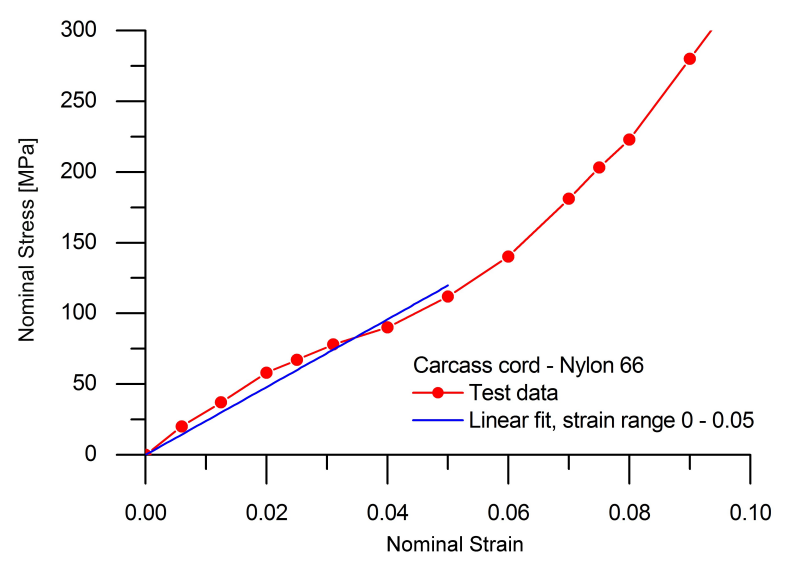

\begin{tabular}{c|c}
\multicolumn{2}{c}{ Linear parameters $(\mathrm{y}=\mathrm{ax}+\mathrm{b})$} \\
{$[\mathrm{MPa}]$ and goodness of fit } \\
\hline $\mathbf{A}$ & 0 \\
$\mathbf{b}$ & 2394.8552 \\
adjusted $\mathbf{R}^{\mathbf{2}}$ & 0.98924 \\
\hline
\end{tabular}

Figure 8. Linear fit on carcass cord data, through zero, narrowed strain range.

Curve fitting for the Yeoh model was performed in Abaqus using all available test data. The resulting curve in uniaxial tension/compression and the obtained model parameters are shown in Figure 9. Poisson's ratio was set to 0.4. The fit was not perfect, but for positive strains it followed the curve better than the linear model, especially in its initial part. The prediction of the negative stress-strain behavior of the nylon cord was not realistic, but further trials showed that it was not possible to obtain a better fit in compression without spoiling the fit in tension.

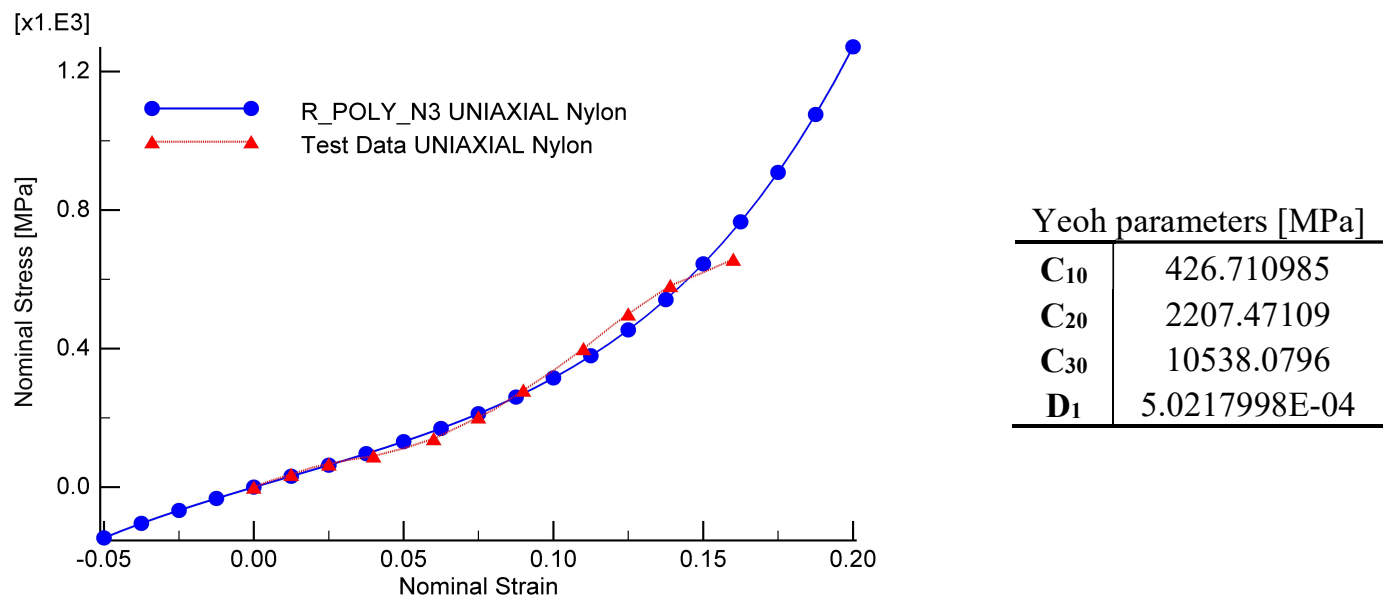

Figure 9. Yeoh model curve in uniaxial tension/compression, positive strain test data only.

Finally, the Marlow model fits were explored. As mentioned, the Marlow model is specific and as a result of fitting no parameters are obtained, but the whole range of material model data (Table 1) is used. As the Marlow model is sensitive to rough data, the use of the Abaqus option for test data smoothing, level 3, was found to be beneficial (Table 1). In order to model compression behavior more realistically, the fit was created with artificial points introduced in compression (Figure 10). 


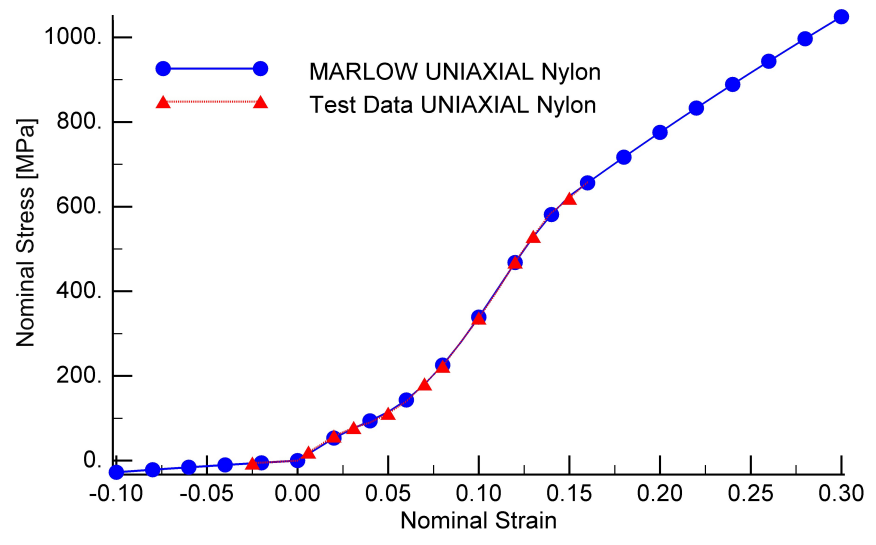

Figure 10. Marlow model curve of nylon cord in uniaxial tension/compression, artificial data points were created in the compression part of the curve.

The test data curve used for steel cord modeling [58] is shown in Figure 11. The data points extracted from the curve are given in Table 2.

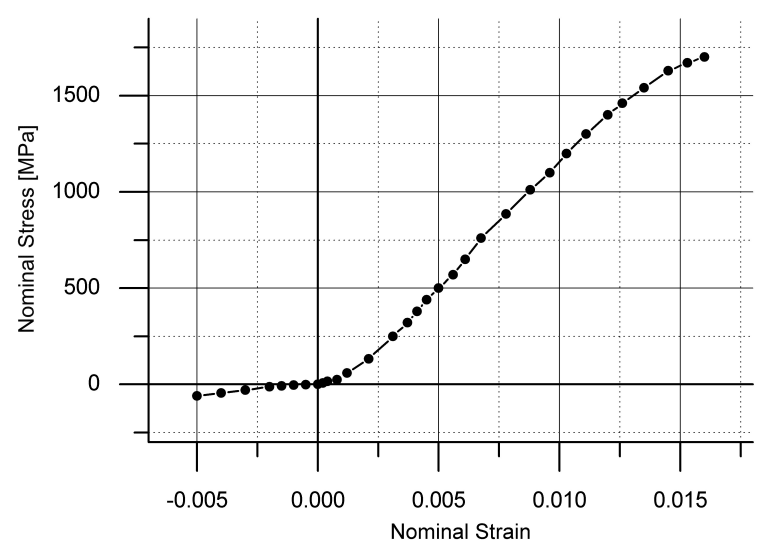

Figure 11. Test data approximated from printed curve - steel cord [58].

Table 2. Data points approximated from the steel cord tension/compression curve shown in Figure 11. The third column represents the smoothed stress obtained during the Marlow model fitting with the data smoothing option, level 2, turned on.

\begin{tabular}{ccccccc}
\hline $\begin{array}{c}\text { Nominal } \\
\text { strain }\end{array}$ & $\begin{array}{c}\text { Nominal } \\
\text { stress [MPa] }\end{array}$ & $\begin{array}{c}\text { Nominal stress } \\
\text { smoothed [MPa] }\end{array}$ & & $\begin{array}{c}\text { Nominal } \\
\text { strain }\end{array}$ & $\begin{array}{c}\text { Nominal } \\
\text { stress [MPa] }\end{array}$ & $\begin{array}{c}\text { Nominal stress } \\
\text { smoothed [MPa] }\end{array}$ \\
\hline-0.0050 & -60.0 & -59.76 & & 0.0045 & 440.0 & 433.39 \\
-0.0040 & -45.0 & -46.03 & & 0.0050 & 500.0 & 499.87 \\
-0.0030 & -30.0 & -28.29 & & 0.0056 & 570.0 & 581.03 \\
-0.0020 & -12.5 & -13.03 & & 0.0061 & 650.0 & 651.28 \\
-0.0015 & -7.5 & -8.67 & & 0.0068 & 760.0 & 743.73 \\
-0.0010 & -3.8 & -7.06 & & 0.0078 & 885.0 & 885.60 \\
-0.0005 & -1.6 & -6.14 & & 0.0088 & 1010.0 & 1011.20 \\
0.0000 & 0.0 & 0.00 & & 0.0096 & 1100.0 & 1110.10 \\
0.0002 & 8.0 & 6.15 & & 0.0103 & 1200.0 & 1197.50 \\
0.0004 & 16.0 & 13.62 & & 0.0111 & 1300.0 & 1295.90 \\
0.0008 & 25.0 & 31.82 & & 0.0120 & 1400.0 & 1398.80 \\
0.0012 & 60.0 & 55.79 & & 0.0126 & 1460.0 & 1461.50 \\
0.0021 & 132.0 & 132.27 & & 0.0135 & 1540.0 & 1546.30 \\
0.0031 & 250.0 & 246.68 & & 0.0145 & 1630.0 & 1625.90
\end{tabular}




\begin{tabular}{|c|c|c|c|c|c|}
\hline 0.0037 & 320.0 & 325.35 & 0.0153 & 1670.0 & 1673.40 \\
\hline 0.0041 & 380.0 & 379.51 & 0.0160 & 1700.0 & 1699.00 \\
\hline
\end{tabular}

The linear fit on steel cord test data is shown in Figure 12. Based on the range of strain estimated from previous tire analyses, the range of positive strain data used for curve fitting was narrowed to $0-0.0041$. This is a compromise fit, as the bilinear material model was not available as a standard option in FEA software. Thus, the elastic modulus in compression is overestimated. All attempts to fit the Yeoh model to steel cord data were not very satisfying, and the acceptable option was found in fitting to tension only data (Figure 13). As it can be seen from the figure, for strains outside the experimental data range the model becomes unstable and the material model curve dives. Material model instability was also reported by the fitting routine. The Marlow model fit is shown in Figure 14. The fit in data range was excellent, and the behavior outside the range was satisfactory. The model was stable for all strains. Nevertheless, the obtained material model curve was a bit wavy, as experimental data was not smooth. According to the literature [44] and previous trials, it could be expected that Marlow models obtained using smoothed data provide better convergence and faster analysis. Thus, the Marlow model fits have also been performed using smoothed data Figure 15.

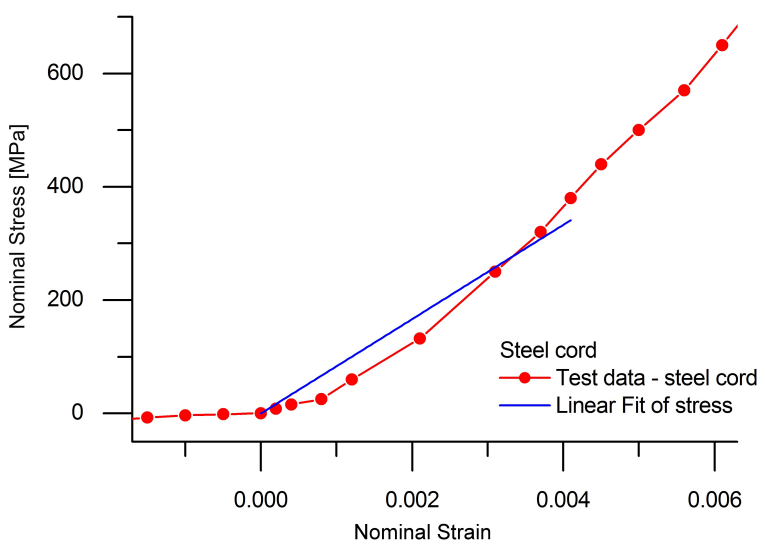

Linear parameters $(\mathrm{y}=\mathrm{ax}+\mathrm{b})$

$[\mathrm{MPa}]$ and goodness of fit

\begin{tabular}{c|c}
\hline $\mathbf{a}$ & 0 \\
$\mathbf{b}$ & 83209.40171 \\
adjusted $\mathbf{R}^{\mathbf{2}}$ & 0.97543 \\
\hline
\end{tabular}

Figure 12. Linear fit to steel data, through zero, for narrowed strain range $(0-0.0041)$.

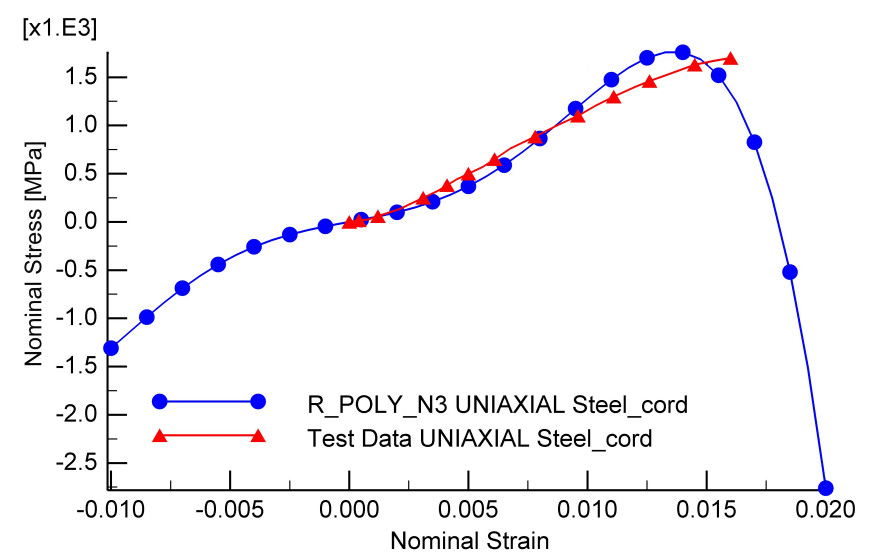

Yeoh parameters $[\mathrm{MPa}]$

\begin{tabular}{l|l}
$\mathrm{C}_{10}$ & 7473.54276
\end{tabular}

$\mathrm{C}_{20} \quad 35871824.2$

$\begin{array}{ll}\mathrm{C}_{30} & -2.754405 \mathrm{E}+10\end{array}$

$\mathrm{D}_{1} \quad 6.17563 \mathrm{E}-05$

Figure 13. Yeoh model curve fit to steel cord data in uniaxial tension/compression, positive strain test data only. 


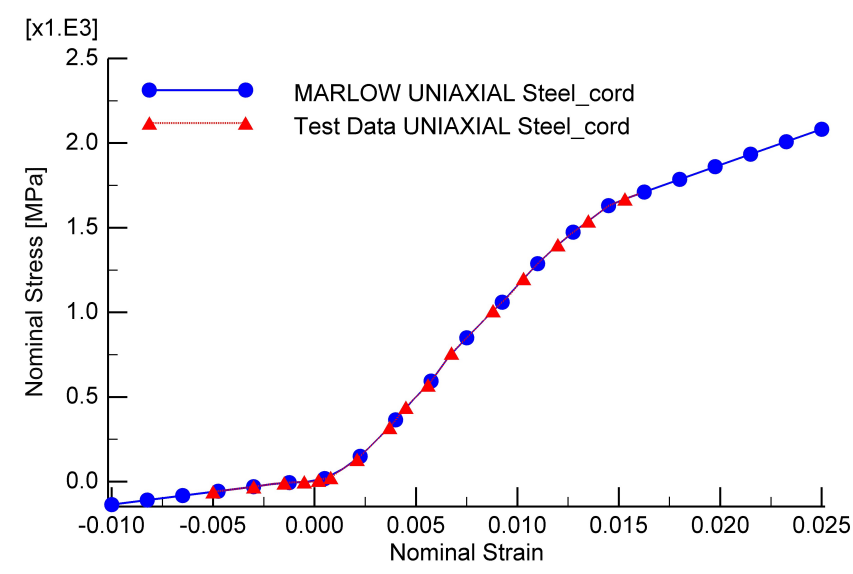

Figure 14. Marlow model curve for steel cord obtained by fitting to whole data range.

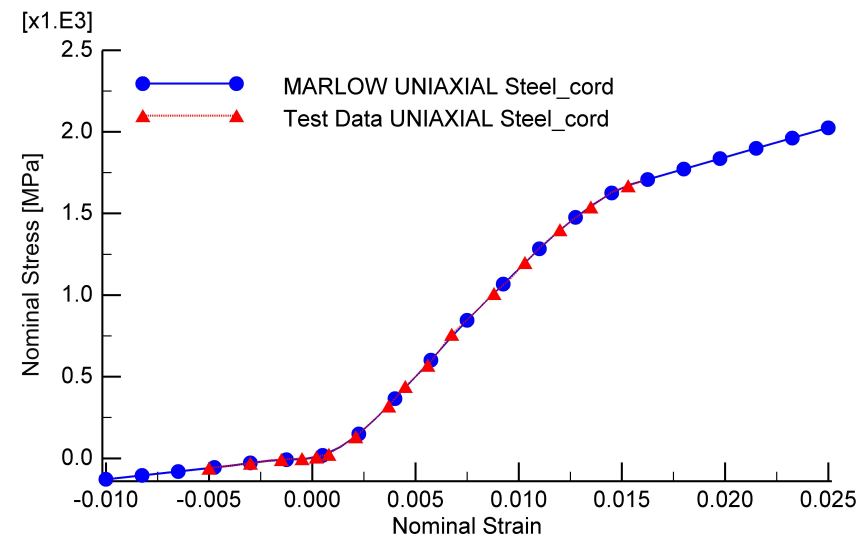

Figure 15. Marlow model curve for steel cord obtained by fitting to whole data range, with test data smoothing parameter equal to 2 .

The list of all material model parameters obtained by curve fitting is given in Table 3 .

Table 3. The list of material model parameters obtained by curve fitting

\begin{tabular}{ccc}
\hline Cord type & Material model & Parameters [MPa] \\
\hline \multirow{3}{*}{ Nylon } & Linear & $\mathrm{a}=0 ; \mathrm{b}=2394.8552$ \\
& Yeoh & $\mathrm{C}_{10}=426.710985 ; \mathrm{C}_{20}=2207.47109 ;$ \\
$\mathrm{C}_{30}=10538.0796$
\end{tabular}


To compare the performance of the selected cord models, structural analyses of an existing 205/55 R16 radial tire model were performed. Two FE models were used: axisymmetric and 3D. In FEA of tires, the rim may be modeled as a separate body, or it may be substituted by equivalent boundary conditions [44]. Within the FE models used in this study, the realistic rim geometry was modeled using rigid surfaces, in order to avoid the artificial stress concentration in the lower sidewall and unrealistic cord behavior in the bead area. FE model variations were created by changing the cord model definitions. All the models were subjected to inflation and footprint analyses.

The axisymmetric FE model (Figure 16 a) consisted of 1029 nodes and 550 finite elements. Rubber was modeled using 4- and 3-node axisymmetric hybrid incompressible elements with twist, and cord was modeled using 2-node axisymmetric surface elements with twist and embedded rebar layers [44]. Bead wire was modeled using standard 4-node axisymmetric elements with twist. The Yeoh material model was used to describe rubber materials and the linear model was used to describe bead wire. The FE mesh of composite sections was created in such a way that only one rebar layer per surface element was used. Thus, the coupling behavior of composites was captured in the best possible way. The 3D model (Figure 16 a) was created by rotating the axisymmetric model with the simultaneous creation of equivalent 3D elements and a 3D rim surface [44], while a rigid surface was added to simulate ground contact. Near the contact zone a denser mesh was created. The model contained 40442 nodes and 18822 elements. The coefficient of friction between tire and rim was set to 1.0, while the frictionless ground contact was used. The procedures used for the FE model creation and tire analysis are described in more detail in [10].
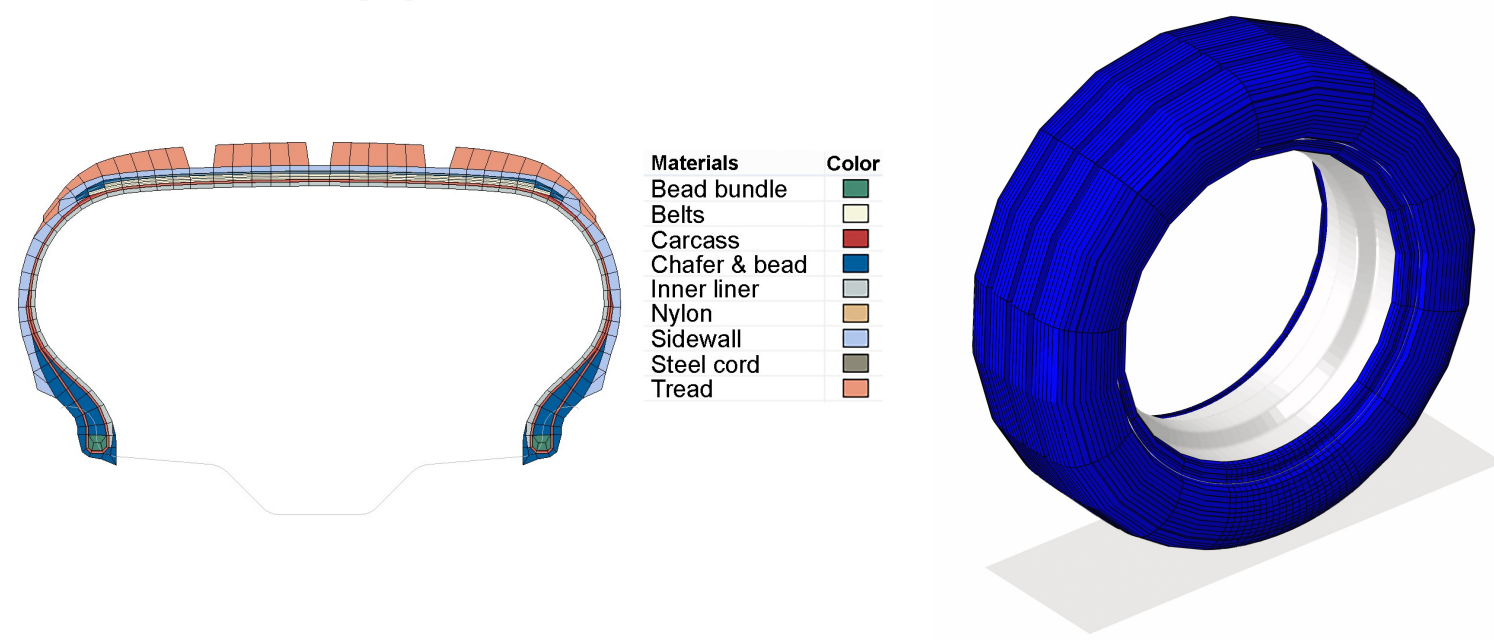

(a)

(b)

Figure 16. Axisymmetric and 3D FE tire models used in the study.

\section{Results}

Material model parameters obtained by fitting to cord test data were input in the previously described FE tire models. The axisymmetric models were subjected to the inner tire pressure of $0.23 \mathrm{MPa}$ and the 3D models were first subjected to the same inner pressure and then to the vertical load of $5443 \mathrm{~N}$. The comparison of the selected analyses results, which were considered as relevant and indicative, was performed and is presented in this chapter.

\subsection{Axisymmetric models - inflation analysis}

The deformed shape of the axisymmetric FE model is shown in Figure 17. As presented in Table 4, the differences between profile dimensions obtained using the axisymmetric models with different cord material definitions are generally small. This is especially true for the two FE models in which the Marlow material model is used to describe the mechanical behavior of cords. 


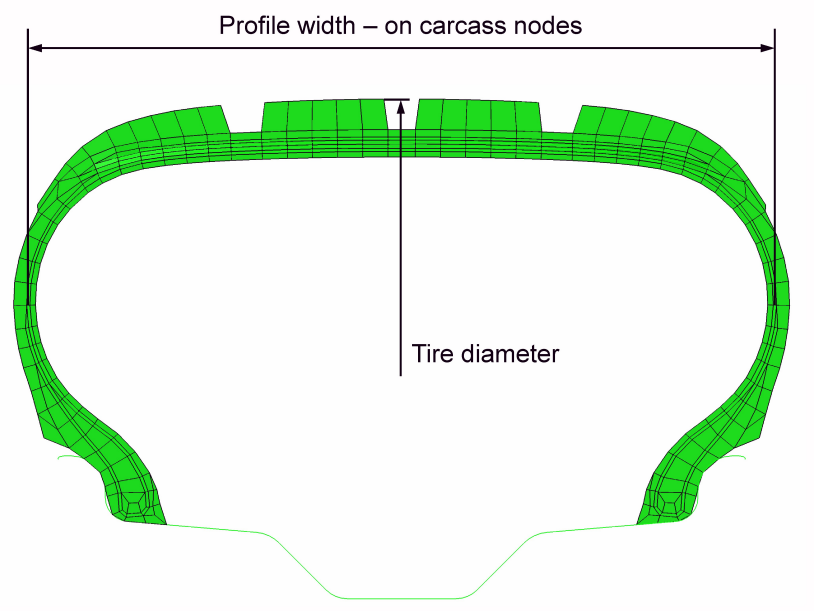

Figure 17. Deformed shape of axisymmetric model and measured values.

Table 4. Differences in predicted profile dimensions for tire models with different cord material definitions

\begin{tabular}{ccc}
\hline Cord model & $\begin{array}{c}\text { Normalized } \\
\text { carcass width }\end{array}$ & $\begin{array}{c}\text { Normalized tire } \\
\text { diameter }\end{array}$ \\
\hline Linear & 1.00000 & 1.000000 \\
Yeoh & 1.00336 & 0.999300 \\
Marlow & 1.00141 & 0.998344 \\
Marlow (smoothed) & 1.00140 & 0.998341 \\
\hline
\end{tabular}

The axial logarithmic strain in belts and cap ply is shown in Figure 18, Figure 19 and Figure 20. At first glance, large differences between predicted cord strains may be observed. If, for example, strain in the middle of the belt obtained using the Yeoh model is compared to the strain obtained using the Marlow model, the difference is as much as $50 \%$, which is probably due to a different behavior of the neighboring carcass in compression. As the Marlow model strictly followed the test data, it was expected to produce the most accurate results.
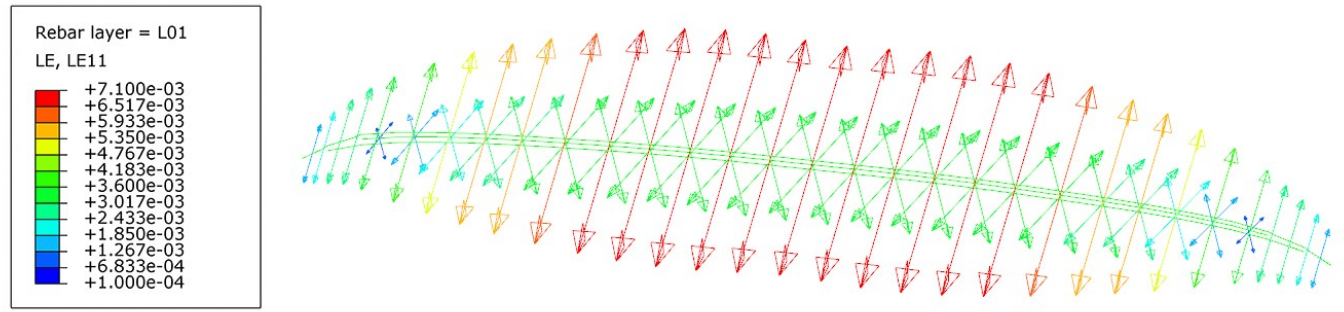

Figure 18. Axial logarithmic strain in belts and cap ply - cords described using the linear material model.
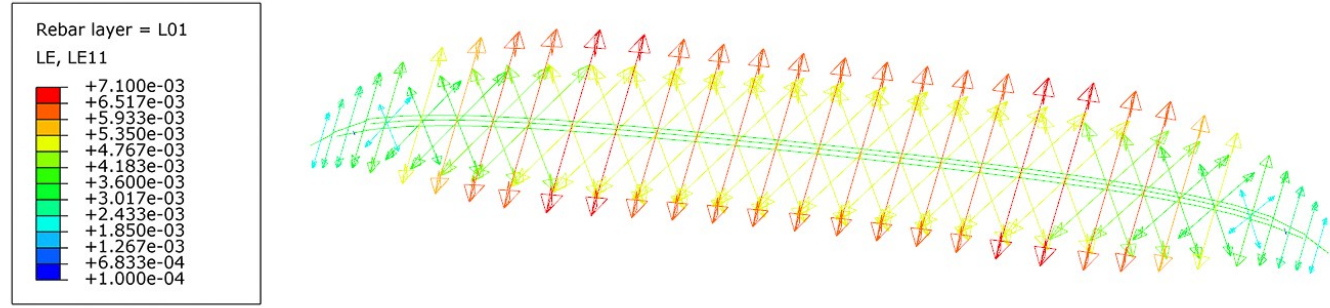

Figure 19. Axial logarithmic strain in belts and cap ply - cords described using the Yeoh material model. 

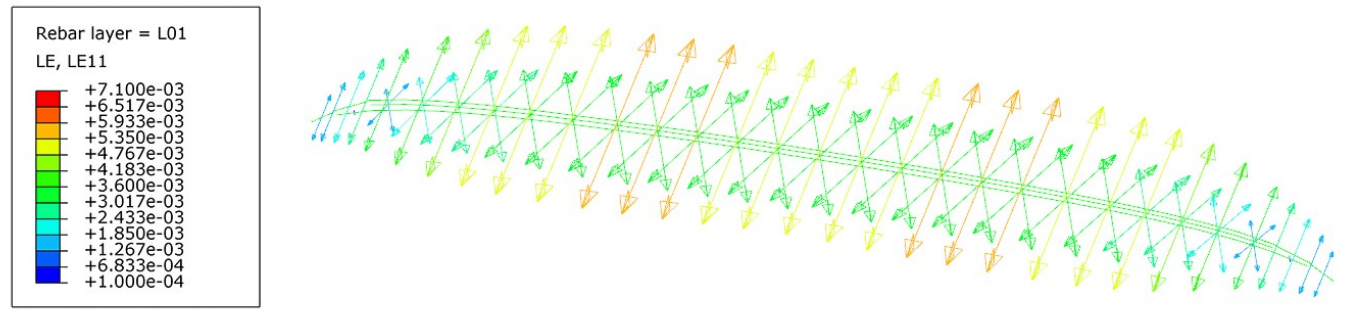

Figure 20. Axial logarithmic strain in belts and cap ply - cords described using the Marlow material model.

Axial stresses in the belt cord obtained using different FE models were not very different (Figure 21 shows the result obtained using the Marlow model). This is expected as in all cases the static equilibrium involves the same inner pressure. The largest difference in maximum belt stress was found to exist between the linear and Yeoh model and it was around 2.5\%. The difference between the Yeoh and Marlow model was only $0.5 \%$.

Stresses in rubber components, obtained using different models, were also very similar, as it is shown in Figure 22, Figure 23 and Figure 24.

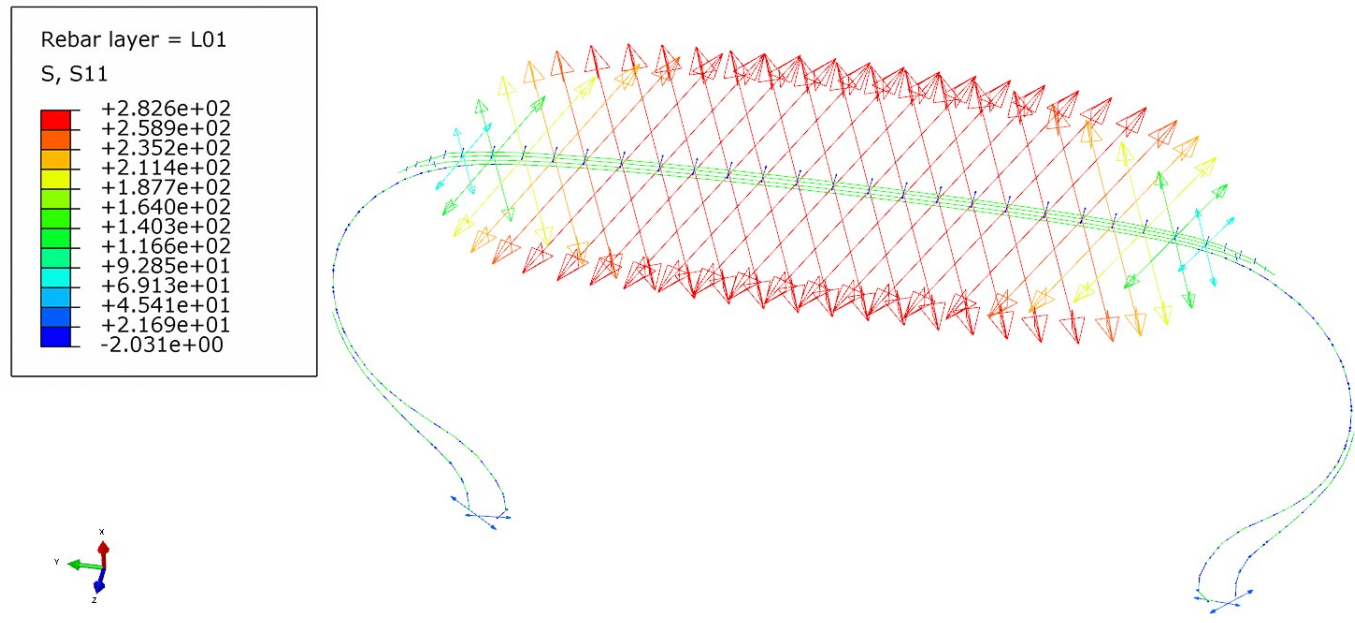

Figure 21. Axial stress - cords described using the Marlow material model, no smoothing.

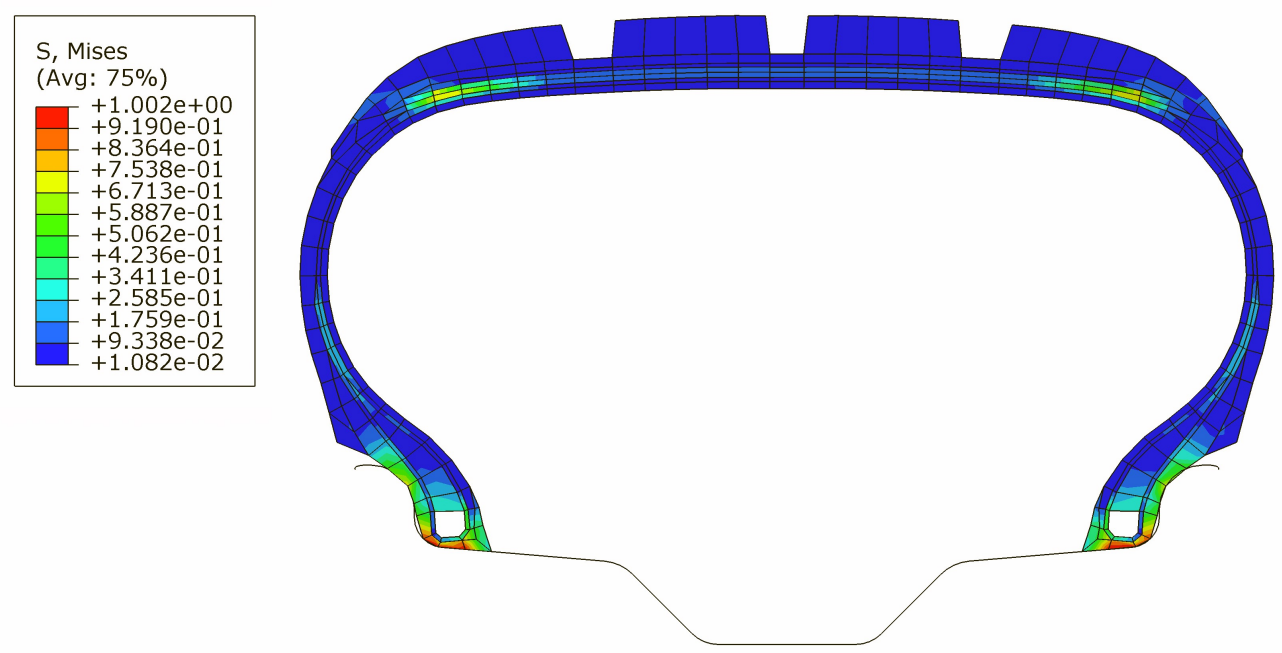

Figure 22. Equivalent stress in rubber components - cords described using the linear material model. 


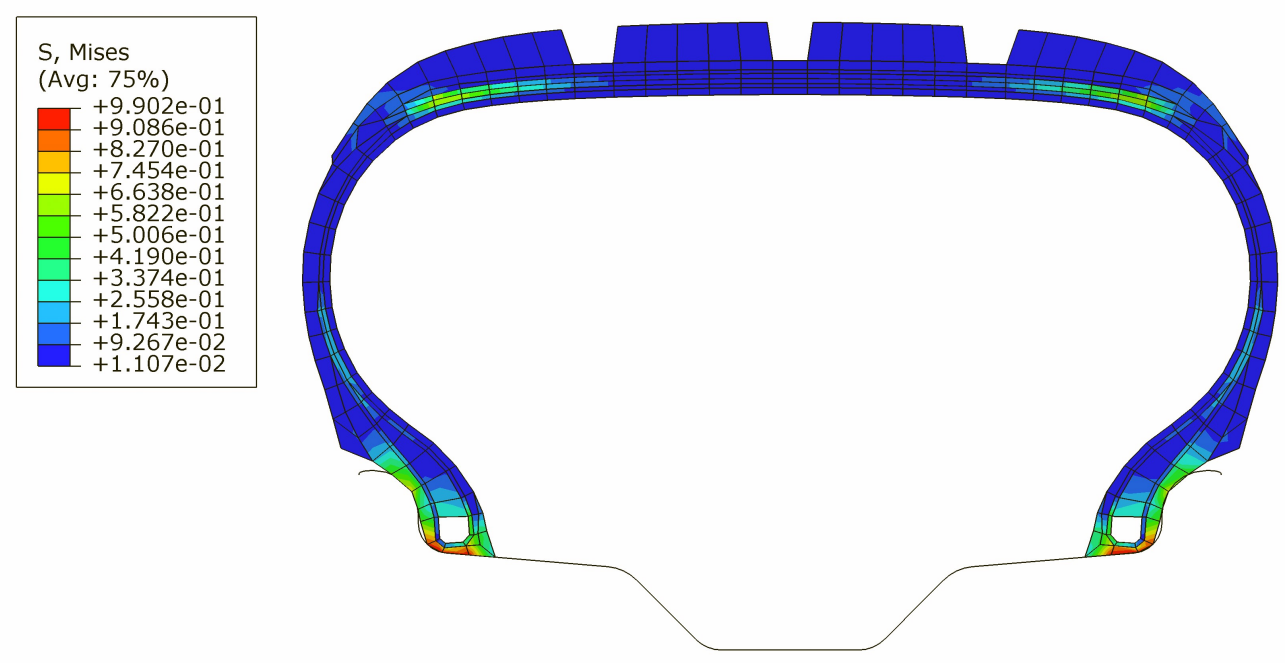

Figure 23. Equivalent stress in rubber components - cords described using the Yeoh material model.

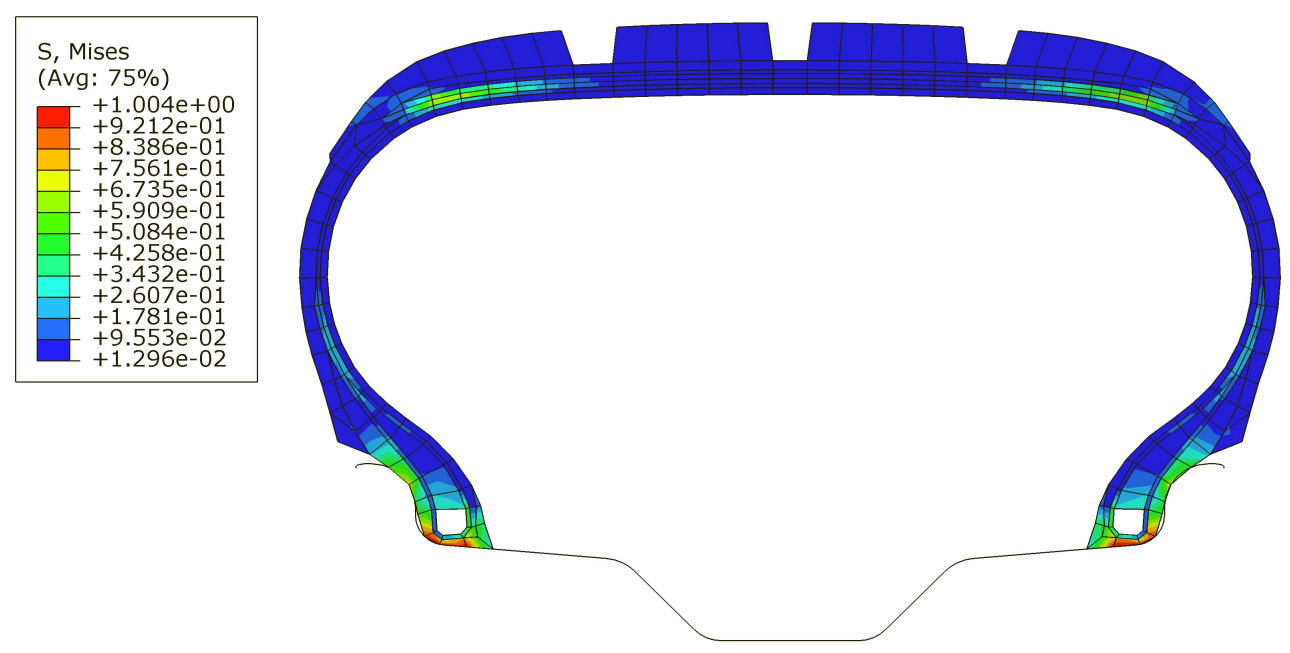

Figure 24. Equivalent stress in rubber components - cords described using the Marlow material model.

The strain energy density distribution in belts and cap ply based on the Marlow model is shown in Figure 25. The distributions for other two models were similar, but there existed a large difference in maximal strain energy density values between different models $\left(0.460 \mathrm{~N} / \mathrm{mm}^{2}\right.$ for linear, $0.646 \mathrm{~N} / \mathrm{mm}^{2}$ for Yeoh and 0.378 $\mathrm{N} / \mathrm{mm}^{2}$ for Marlow), which may be important for considerations regarding durability and rolling resistance.
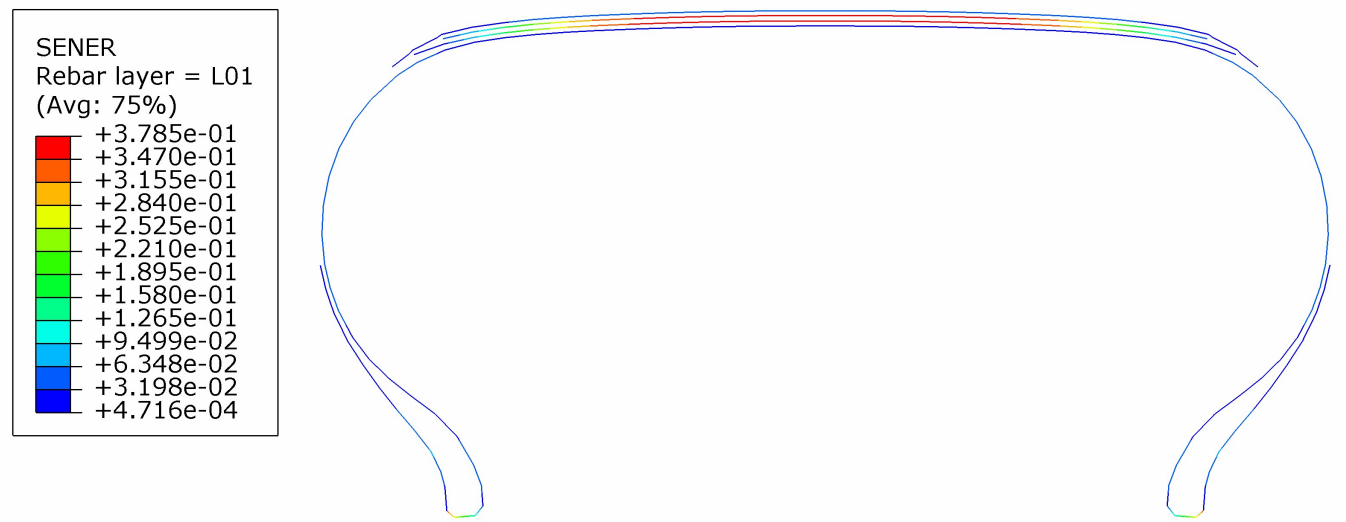

Figure 25. Strain energy density in belt and cap ply - cords described using the Marlow material model. 


\subsection{D models - footprint analysis}

The footprint analysis of the 3D tire FEA models with the Yeoh material model used to describe cords did not converge, which is not unexpected concerning a very bad fit of the Yeoh model to nylon cord test data and material model instability (Figure 13). Thus, the results in this chapter are shown for the linear and Marlow models only.

The load-deflection curves obtained using different models are very close to each other (Figure 26). The curves obtained using the FE model containing the Marlow-based cord definitions are more non-linear than the curve obtained using the FE model containing the linear cord definitions. The curves obtained using the unsmoothed and smoothed Marlow belt cord definitions are almost identical, although the load-deflection step of the analysis using the smoothed model was completed in considerably fewer iterations than the load-deflection step of the analysis using the unsmoothed model. Thus, smoothing did not considerably affect the accuracy of the calculation, but the analysis was completed much faster.

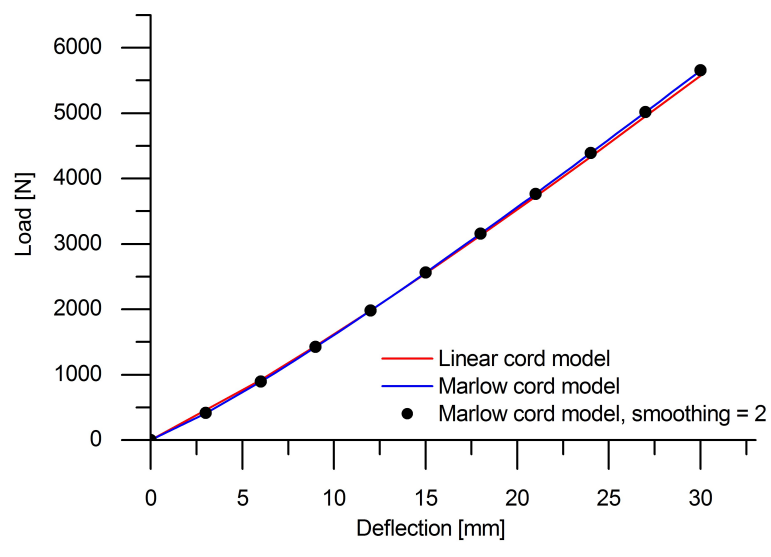

Figure 26. Load - deflection curves obtained by FEA of the 3D tire models with different cord definitions.

The contact pressure distribution at the footprint is shown in Figure 27, Figure 28 and Figure 29. However, it is not considerably different between various models and the difference is best seen in Figure 29.

Finally, the strain energy density distribution calculated using the 3D tire models with different cord material definitions is shown in Figure 30. There is also a significant difference in maximal values as in the case of the axisymmetric models.
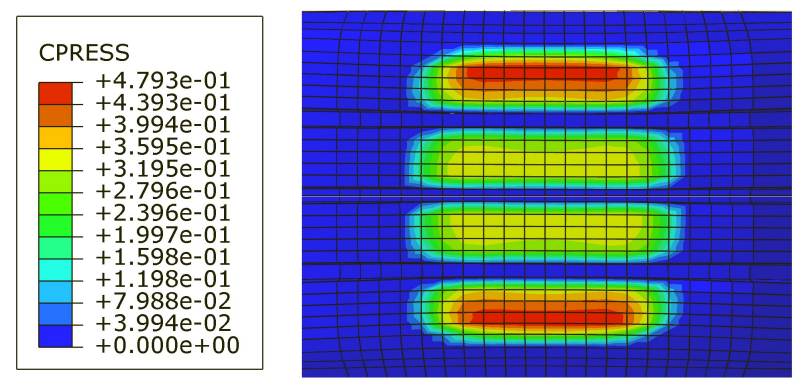

Figure 27. Contact stress at the footprint - cords described using the linear material model.
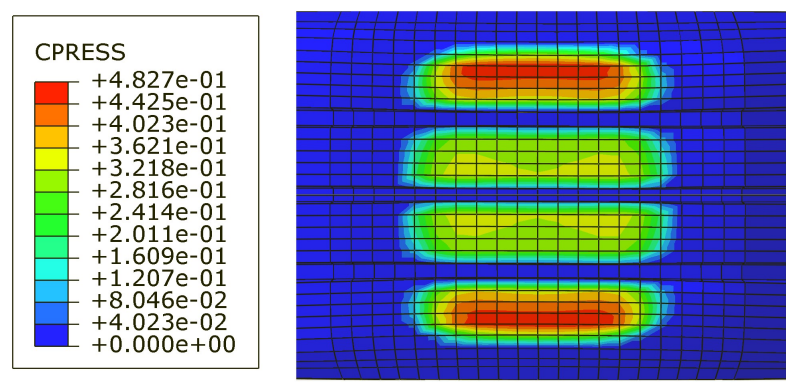
Figure 28. Contact stress at the footprint - cords described using the Marlow material model.

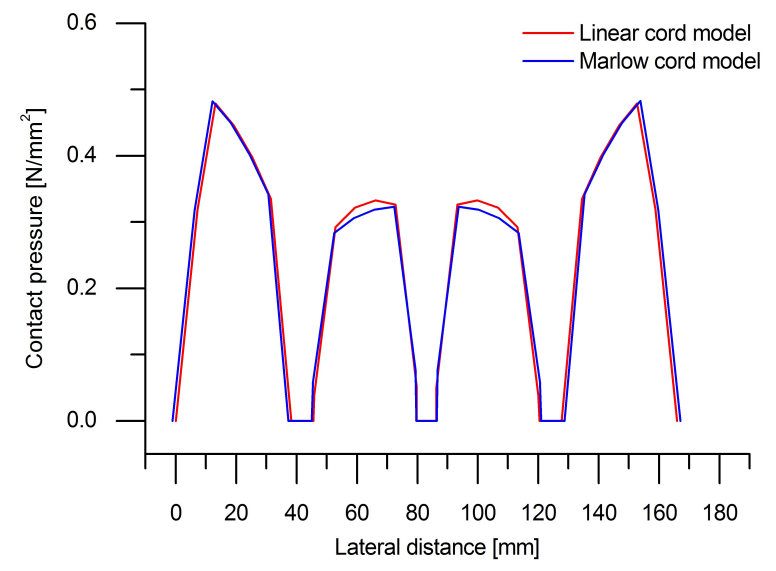

Figure 29. Contact stress distribution along the lateral line, in the middle of the footprint.

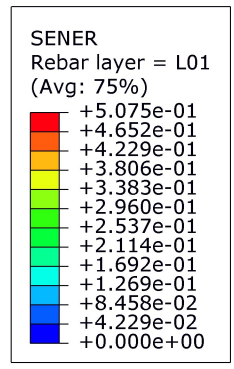

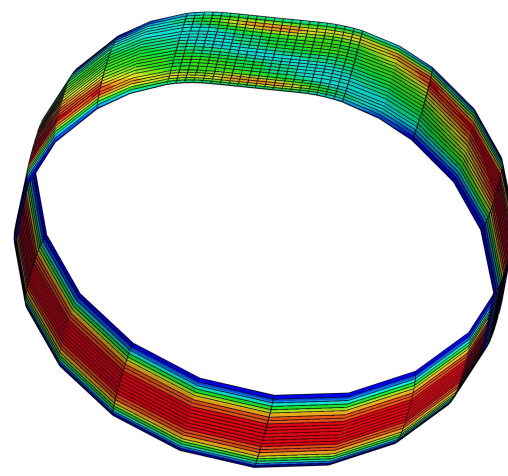

(a)

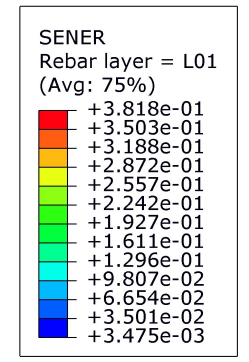

(b)

Figure 30. Strain energy density in outer belt: (a) linear cord model, (b) Marlow cord model.

Analysis run times are shown in Table 5. The 3D model based on the Yeoh cord definitions did not converge and is not taken into account. Repeated model fitting trials would probably lead to convergence. As expected, the Marlow material model, which is the most accurate one, also increased the analysis time. Nevertheless, the use of the smoothed Marlow model for the belt cord resulted in a notably shorter analysis time compared to the unsmoothed one.

Table 5. Run times

\begin{tabular}{ccccc}
\hline & \multicolumn{2}{c}{$\begin{array}{c}\text { Run time on Intel i7-2630QM [s] } \\
\text { Axisymmetric }\end{array}$} & \multicolumn{2}{c}{ Normalized run time } \\
Cord model & 15 & 3D footprint & $\begin{array}{c}\text { Axisymmetric } \\
\text { inflation }\end{array}$ & 3D footprint \\
\hline Linear & 12 & 637 & 1.00 & 1.00 \\
Yeoh & 20 & did not converge & 0.80 & - \\
Marlow & 17 & 1234 & 1.33 & 1.94 \\
Marlow (smoothing=2) & 696 & 1.13 & 1.09 \\
\hline
\end{tabular}

Based on the study results, a comparison of the material model features is given in Table 6. 
Table 6. The comparison of cord material model features

\begin{tabular}{|c|c|c|c|}
\hline $\begin{array}{c}\text { Material } \\
\text { model }\end{array}$ & Cord modeling accuracy & Curve fitting & $\begin{array}{c}\text { Computational } \\
\text { efficiency }\end{array}$ \\
\hline Linear & $\begin{array}{l}\text { Insufficient at larger strains or } \\
\text { for simultaneous modeling of } \\
\text { tension and compression }\end{array}$ & Easy & Fast \\
\hline Bilinear & $\begin{array}{l}\text { Insufficient for } \\
\text { larger strains }\end{array}$ & $\begin{array}{l}\text { Relatively easy, tension } \\
\text { and compression must be } \\
\text { fitted separately }\end{array}$ & Fast \\
\hline $\begin{array}{l}\text { Linear - } \\
\text { tension only }\end{array}$ & $\begin{array}{l}\text { Insufficient for larger strains, no } \\
\text { modulus in compression }\end{array}$ & Easy & Fast \\
\hline Yeoh & $\begin{array}{l}\text { Fair for nylon, } \\
\text { inaccurate for steel }\end{array}$ & $\begin{array}{c}\text { Problematic fitting, especially } \\
\text { for steel, multiple trials often } \\
\text { necessary }\end{array}$ & Slower \\
\hline Marlow & Very accurate & Easy, requires smooth data & The slowest \\
\hline $\begin{array}{l}\text { Marlow with } \\
\text { data } \\
\text { smoothing }\end{array}$ & Very accurate & Easy & $\begin{array}{l}\text { Slower than Yeoh, } \\
\text { faster than Marlow }\end{array}$ \\
\hline
\end{tabular}

\section{Conclusions}

The use of non-linear vs. linear cord material models was discussed in the paper and illustrated through sample FEA performed on a realistic tire model. The basic principles related to tire cord modeling for FEA were also presented, as well as typical mechanical properties of tire cord and related test methods.

Linear material models were found to be simple, fast to fit and calculate, but did not capture the nonlinear behavior of cord. The Yeoh model could represent nonlinear behavior and produce smooth fitting curves, but it could not accurately approximate the specific shape of the stress-strain curve of tire cord, especially in compression. The Marlow model produced very accurate fits based on tension data only, but it required smooth test data, caused slower convergence and needed more computational resources. The use of the data smoothing option during the identification of the Marlow model parameters yielded significant improvements in computational efficiency of tire FEA.

The difference between the resulting tire dimensions and stresses in tire cord, obtained using various material models, was not very significant. Nevertheless, there were notable differences in strains as well as in strain energy density. Thus, for proper structural reinforcement design, for the prediction of local effects that influence tire durability or calculations related to rolling resistance, the use of nonlinear cord material models may be very important.

The recommended choice for material modeling of all tire cords is the Marlow model, which showed great accuracy in curve fitting to experimental data without a significant deterioration of analysis times, thanks to the test data smoothing option. For this model to be accurate, the accurate test data are also necessary.

\section{Data availability}

The raw/processed data required to reproduce these findings, related to tire geometry, cannot be shared at this time due to legal or ethical reasons. The raw/processed data related to material testing and modeling, which is based on publicly available resources, is presented in the tables.

\section{References}

[1] Gent AN, Walter JD. The Pneumatic Tire. Washington D.C.: National Higway Traffic Safety Administration, U.S. Department of Transportation, 2006.

[2] Clark SK. The Mechanics of Pneumatic Tires. Washington, D. C.: National Bureau of Standards, U. S. Govt. Printing Office, 1971.

[3] Walter JD. Tire materials and manufacturing, Presentation from 39th Tire Mechanics Short Course. Köln2013.

[4] Tong L, Mouritz AP, Bannister M. 3D fibre reinforced polymer composites: Elsevier, 2002.

[5] McDonel E. Tire cord and cord-to-rubber bonding. The pneumatic tire. 2006:80. 
[6] Nakajima Y. Application of Computational Mechanics to Tire Design-Yesterday, Today, and Tomorrow. Tire Science and Technology. 2011;39:223-44.

[7] Ghoreishy MHR. A State of the Art Review of the Finite Element Modelling of Rolling Tyres. Iranian Polymer Journal. 2008;18:571-97.

[8] Kabe K, Koishi M. Tire cornering simulation using finite element analysis. Journal of Applied Polymer Science. 2000;78:1566-72.

[9] Korunović N, Trajanović M, Stojković M. FEA of tyres subjected to static loading. Journal of Serbian Society for Computational Mechanics. 2007;1:87-98.

[10] Korunović N, Trajanović M, Stojković M. Finite element model for steady-state rolling tire analysis. Journal of Serbian Society for Computational Mechanics. 2008;2:63-79.

[11] Brinkmeier M, Nackenhorst U, Volk H. A finite element approach to the transient dynamics of rolling tires with emphasis on rolling noise simulation. Tire Science and Technology. 2007;35:165-82.

[12] Wei C, Olatunbosun OA. Transient dynamic behaviour of finite element tire traversing obstacles with different heights. Journal of Terramechanics. 2014;56:1-16.

[13] Behnke R, Kaliske M. Thermo-mechanically coupled investigation of steady state rolling tires by numerical simulation and experiment. International Journal of Non-Linear Mechanics. 2015;68:101-31.

[14] Suwannachit A, Nackenhorst U. A Novel Approach for Thermomechanical Analysis of Stationary Rolling Tires within an ALE-Kinematic Framework. Tire Science and Technology. 2013;41:174-95.

[15] Abe A, Kamegawa T, Nakajima Y. Optimization of construction of tire reinforcement by genetic algorithm. Optimization and Engineering. 2004;5:77-92.

[16] Serafinska A, Hassoun N, Kaliske M. Numerical optimization of wear performance-Utilizing a metamodel based friction law. Computers \& Structures. 2016;165:10-23.

[17] Jones RM. Mechanics of composite materials: CRC press, 2014.

[18] Helnwein P, Liu CH, Meschke G, Mang HA. A new 3-D finite element model for cord-reinforced rubber compositesapplication to analysis of automobile tires. Finite Elements in Analysis and Design. 1993;14:1-16.

[19] Charlton D, Yang J, Teh K. A review of methods to characterize rubber elastic behavior for use in finite element analysis. Rubber Chemistry and technology. 1994;67:481-503.

[20] Boyce MC, Arruda EM. Constitutive models of rubber elasticity: a review. Rubber Chemistry and technology. 2000;73:504-23.

[21] Olatunbosun OA, Bolarinwa O. FE Simulation of the Effect of Tire Design Parameters on Lateral Forces and Moments Tire Science \& Technology. 2004;32:146-63.

[22] Tönük E, Ünlüsoy YS. Prediction of automobile tire cornering force characteristics by finite element modeling and analysis. Computers \& Structures. 2001;79:1219-32.

[23] Manić D. The Practical Tyre Guide. Pirot: TIGAR Pirot Tyre Plant; 2000.

[24] Koutny F. Geometry and mechanics of pneumatic tires. Zlin: CZE-2007,-142 p. 2007.

[25] Du X, Qu W, Wan Z, Ma H, Yao M, Jiang J. Reinforcing function of polymer cords embedded in rubber under compression. Tire Science and Technology. 1992;20:254-64.

[26] Group BCES. Tire Cord Dynamic Properties Measured for FEA Model. 2012.

[27] Chen B. Material Characterization of Tire Cords and the Effects of Cord Thermal-Mechanical Properties on Tires. Tire Science and Technology. 2004;32:2-22.

[28] ASTM. D 2969 - 02 Standard Test Methods for Steel Tire Cords. ASTM International, 100 Barr Harbor Drive, PO Box C700, West Conshohocken, PA 19428-2959, United States.; 2002. p. 17.

[29] ASTM. D 885 - 03 Standard Test Methods for Tire Cords, Tire Cord Fabrics, and Industrial Filament Yarns Made from Manufactured Organic-Base Fibers. ASTM International, 100 Barr Harbor Drive, PO Box C700, West Conshohocken, PA 19428-2959, United States; 2003. p. 31.

[30] Cho J, Lee S, Jeong H-Y. Finite element analysis of a tire using an equivalent cord model. Finite Elements in Analysis and Design. 2015;105:26-32.

[31] Shield C, Costello G. The effect of wire rope mechanics on the mechanical response of cord composite laminates: an energy approach. Journal of applied mechanics. 1994;61:9-15.

[32] Shield CK, Costello GA. Bending of cord composite plates. Journal of engineering mechanics. 1994;120:876-92.

[33] Pidaparti R. Analysis of cord-rubber composite laminates under combined tension and torsion loading. Composites Part B: Engineering. 1997;28:433-8.

[34] Kocak RP, S. Three-dimensional micromechanical modeling of cord-rubber composites. Mechanics of Composite Materials and Structures. 2000;7:19-34.

[35] Yintao W, Yiwen L, Yiming M, Delong C, Xijin F. Finite element modeling for steel cord analysis in radial tires. Tire Science and Technology. 2013;41:60-79.

[36] Walter J, Avgeropoulos G, Janssen M, Potts G. Advances in tire composite theory. Tire Science and Technology. 1973;1:210-50.

[37] Brewer H. Tire stress and deformation from composite theory. Tire Science and Technology. 1973;1:47-76.

[38] Patel H, Turner J, Walter JD. Radial tire cord-rubber composites. Rubber Chemistry and technology. 1976;49:1095-110.

[39] Ridha R. Computation of stresses, strains, and deformations of tires. Rubber Chemistry and technology. 1980;53:849902.

[40] Ridha R, Theves M. Advances in tyre mechanics: iSmithers Rapra Publishing, 1994.

[41] Levin V, Zingerman K, Vershinin A, Yakovlev MY. Numerical analysis of effective mechanical properties of rubbercord composites under finite strains. Composite structures. 2015;131:25-36.

[42] Meschke G, Payer HJ, Mang HA. 3D Simulations of Automobile Tires: Material Modeling, Mesh Generation, and Solution Strategies. Tire Science \& Technology. 1997;25. 
[43] Kondé AK, Rosu I, Lebon F, Brardo O, Devésa B. On the modeling of aircraft tire. Aerospace Science and Technology. 2013;27:67-75.

[44] Simulia. ABAQUS Version 2018 HTML Documentation. Dassault Systèmes; 2018.

[45] Marc M, Volume A. Theory and user information. Santa Ana: MSC Corp. 2010.

[46] Meschke G, Helnwein P. Large-strain 3D-analysis of fibre-reinforced composites using rebar elements: hyperelastic formulations for cords. Computational Mechanics. 1994;13:241-54.

[47] Behnke R, Kaliske M. Finite Element Based Analysis of Reinforcing Cords in Rolling Tires: Influence of Mechanical and Thermal Cord Properties on Tire Response. Tire Science and Technology. 2018;46:294-327.

[48] Behroozinia P, Taheri S, Mirzaeifar R. An investigation of intelligent tires using multiscale modeling of cord-rubber composites. Mechanics Based Design of Structures and Machines. 2018;46:168-83.

[49] Rohwer K. Models for intralaminar damage and failure of fiber composites-a review. Facta Universitatis, Series: Mechanical Engineering. 2016;14:1-19.

[50] Ghoreishy M. Steady state rolling analysis of a radial tyre: comparison with experimental results. Proceedings of the Institution of Mechanical Engineers, Part D: Journal of Automobile Engineering. 2006;220:713-21.

[51] Ogden RW. Non-linear elastic deformations: Courier Corporation, 1997.

[52] Gough J, Gregory I, Muhr A. Determination of constitutive equations for vulcanized rubber. Finite element analysis of elastomers. 1999:5-26.

[53] Yeoh OH. Characterization of elastic properties of carbon-black-filled rubber vulcanizates. Rubber Chemistry and technology. 1990;63:792-805.

[54] Yeoh $\mathrm{OH}$, Fleming P. A new attempt to reconcile the statistical and phenomenological theories of rubber elasticity. Journal of Polymer Science Part B: Polymer Physics. 1997;35:1919-31.

[55] Marlow R. A general first-invariant hyperelastic constitutive model. Constitutive Models for Rubber. 2003:157-60.

[56] Ogden RW. Large deformation isotropic elasticity-on the correlation of theory and experiment for incompressible rubberlike solids. Proceedings of the Royal Society of London A Mathematical and Physical Sciences. 1972;326:565-84.

[57] Ghoreishy M. Hyperelastic Constitutive Models Using FEA of Rubbers: A Study. Tire Technology International: Int; 2010.

[58] Ghosh S. Investigation on role of fillers on viscoelastic properties of tire tread compounds. Vadodara: Maharaja Sayajirao University of Baroda, 2011. 